\title{
CORRIGENDUM
}

\section{Measured haplotype analysis of the aldosterone synthase gene and heart size}

\author{
Bongani M Mayosi, Bernard Keavney, Hugh Watkins and Martin Farrall
}

European Journal of Human Genetics (2005) 13, 992 . doi:10.1038/sj.ejhg.5201427

Correction to: European Journal of Human Genetics (2003) 11, 395-401. doi:10.1038/sj.ejhg.5200967

The authors have identified a typing error in this article. The G5937C polymorphism of the aldosterone synthase gene is in fact a G5937A change (SNP rs3097 in the NCBI SNP database). The error was recorded after the genotyping was performed, and does not affect the scientific validity of the study.

The authors noticed this typing error in a subsequent study based on the same genotype information, which was published recently with the correct genotype information (Keavney B et al. J Clin Endocrinol Metab. 2005; 90: 1072-1077). 